\title{
WORKING WITH PEOPLE MODEL AS A METHODOLOGICAL APPROACH TO ENHANCE SOCIAL CAPITAL IN SPANISH RURAL AREAS
}

\begin{abstract}
Miriam LÓPEZ GONZÁLEZ, Sustainable Rural Development at the Agroforestry Department, Technical University of Madrid (UPM), Escuela Superior de Ingenieros Agrónomos, Av. Complutense s/n, Spain, miriam.lopez@upm.es (corresponding author)

Raquel PASTOR CARRETERO, Project Planning for Rural Development and Sustainable Management at the Agroforestry Department of the Technical University of Madrid (UPM), Escuela Superior de Ingenieros Agrónomos, Av. Complutense s/n, Spain, raquel.pastor.carretero@upm.es

Gilberto Segundo BRITO ASTUDILLO, Universidad del Azuay, Ave 24 de Mayo 7-77, Cuenca 01.01.981, Ecuador, gbrito@ups.edu.ec

Social capital (SC) has been understood as a set of relationships among structures inherent in the society. These social structures seek a common goal for the greatest number of people. The main purpose of this research is to study how social capital can be generated through the three components of the Working With People model: technical-entrepreneurial; ethical-social and political-contextual. This research is based on a Program developed in seventeen municipalities of Avila, a Spanish province in the northern Spanish plateau. The Program is called "Young Entrepreneurs for Sustainability in Rural Areas", promoted by Tatiana Perez de Guzman el Bueno Foundation and carried out by Gesplan Group from the Technical University of Madrid. This Program consists on launching innovative projects in the territory focused on promoting partnerships among the population and to develop the territory through economic initiatives. The aim of these actions is to strengthen relationships between institutions and the population. This is possible by the creation of synergies among the entrepreneurial projects in order to get endogenous development.
\end{abstract}

Keywords: social capital, entrepreneurship, rural development, endogenous development.

\section{INTRODUCTION}

The importance of the social capital concept has been increasing in the last decades not only in the political or economic fields but also in different research areas (Bhandari and Yasunobu, 2009). Social capital is based on the theory that human capital and physical capital are not enough to promote neither economic growth nor a communities' economic development. Portes (2000) summarize the three kinds of capital, where human capital is inside people's head, economic capital is in people's bank, and social capital inheres in the structure of people's relationships. Networks, trust, and information-flows to control resources should also be taken into account (Hjerppe, 1998; Woolcock, 1998; Fafchamps, 2004). Due to this broad conceptualization of terms and subcomponents, different approaches have been developed but, nevertheless, a clear definition has not been defined, creating confusion in the literature on the subject (Sastre-Merino and Fernández-Moral, 2012). The first author who talked about this concept was L. J. Hanifan on his publication "The Rural School Community Center". Hanifan lays the basis of social capital concept, defining it:

Not such as the usual acceptation of the term capital but rather to that in life which tends to make these tangible substances count for most in the daily lives of a people, namely, good-will, fellowship, mutual sympathy and social intercourse among a group of individuals and families who make up a social unit. In a community building as in business organization and expansion there must be an accumulation of capital before constructive work can be done. In building up a large business enterprise of modern proportions, there must be an accumulation of capital from a large number of individuals.

Subsequently, the concept of social capital has been developed by many authors conferring to the concept a multidimensional significance, while Bordieu (1986) defines the concept as permanents networks to assure a set of resources; Coleman (1988) as social structures to facilitate actions among the agents; or Fukuyama (1995) as values or norms established in society and shared among members of a group to cooperate. Finally, Putnam (1995) emphasizes that the importance of social capital concept lies on interactions and connections required sustaining the society. Specifically for this author, social capital is defined as aspects of social organizations such as networks, norms and confidence which facilitate action and cooperation for a mutual benefit. In rural development programs, there are some considerations in order to

Copyright (C) 2015 The Authors. Published by Aleksandras Stulginskis University. This is an open-access article distributed under the terms of the Creative Commons Attribution License (CC-BY 4.0), which permits unrestricted use, distribution, and reproduction in any medium, provided the original author and source are credited. 
generate social capital such as promoting an environment based on equitable criteria or providing an environment governed by rules, favoring confidence and transparency (Stolle, 2003; Bowles and Gintis, 2004; Michelini, 2013). Last consideration according to rural development projects is participation (Michelini, 2013). Participation increases the generation of different kinds of capital and it involves consensus, trust and social learning (Cohen and Uphoff, 1980; Narayan-Parker, 1999).

Planning has generally been used as an engineering tool for predicting future actions or making plans but new concept of planning arise to satisfy current and future needs of society, focused on the present to mobilize resources in order to produce an economic and social welfare (Cazorla et al., 2006). The modern planning model has been focused on seeking involvement of influential agents and stakeholders in order to achieve sustainable projects in time, trying to focus efforts to become sustainable, and to expand the overview of their social and environmental effects (Gallegos et al., 2012). Society is constituted by different levels and limited by blurred borders with social conflicts among them, and for this reason, decision making must be based on negotiation and dialogue. In agreement with Friedmann (1987), four planning theories have been developed in society and this classification depends on the decision making process and the origin of this decision. Policy analysis, social learning, social reform, and, social mobilization are the four models defined by Friedmann. In any of them, there is a mainly domain which makes decision in order to achieve the goals. These practical domains are the State, the Political Community, the Society, and the Corporative Economy (Friedman, 1992). Relationships among these domains should be created through negotiation, agreement, trust, and dialogue, which could be considered as the components to generate social capital. Thus, social capital can be considered one of the primarily results of a planning based on collaborative process es among the agents (Mandarano, 2009). According to Friedmann's planning models, the importance of collaborative processes depends on where the decision making is located. In this manner, Social Reform is based on technical reason and rationality where the paradigm of planning is based on top-down approach. Secondly, Policy Analysis is based in the same top-down approach but the difference lies on bureaucracy (Friedmann, 1987). In this regard, Policy Analysis is seen as an internal function of governance, advised by the experts to make decisions, supported by assessments and sophisticated models of simulation. Thirdly, Social Mobilization is characterized by a radical tendency which its deepest roots are in the three oppositional movements of utopianism, social anarchism, and historical materialism and is characterized by the spontaneous opposition and the principles of mutualism and cooperation. Finally, Social Learning model is a correlative process between knowledge and action, and it involves the action itself, tactics and political strategy, theories of reality, and values. In this last model, decisions are embedded in a learning process that flows from the attempt to change reality through practice. In this model, actor and learner are assumed to be one and the same and involve agents who encourage, guide, and assist an actor in the process of changing reality. They are generally professionals who bring certain kinds of formal knowledge to the ongoing social practice of their group.

The main purpose of this research is to study the capacity to generate social capital in the territory through the three pillars of Working With People model (Cazorla et al., 2013), which shares principles and values with the Social Learning planning such as bottom-up multidisciplinary view or boosting development from an endogenous approach. Above all, the relationship between social learning planning model and the generation of social capital has been studied throughout a participatory process which includes workshops, interviews, etc. The theoretical framework will be discussed according to findings.

\section{CASE STUDY}

The case study of this research is based on a pilot program called "Young Entrepreneurs for Sustainability of Rural Areas", (JESTeR for its acronym in Spanish), included in the rural development program of Tatiana Pérez de Guzmán el Bueno Foundation. The main purpose is to foster the development of seventeen municipalities in Ávila as well as activating the existing endogenous potential in this territory. These municipalities are part of the program territorial domain located in the region of Sierra de Ávila. The population of the territory is around 1600 inhabitants and this territory occupies an extension of about $379 \mathrm{~km}^{2}$ with a low population density, only 4.42 inhabitants per $\mathrm{km}^{2}$, data below the average national density which stands in 93,43 inhabitants per $\mathrm{km}^{2}$. The territory presents countless productive, cultural and environmental resources that enable the establishment of synergies between the local factors. In the Program's framework is established, first of all, the necessity to specify an entrepreneurial strategy to foster population's initiatives. To that end, participatory activities have been realized with the aim to identify the potential entrepreneurs and future project ideas. On the other hand, the Program seeks to develop and sustain educational actions to design a Capacity Building Plan to assure the empowerment of the human resources existing in the territory and encourage the launch of the projects and its success.

In this regard, the technical team as its planner position assumes an intermediary roll between institutions and population but also among the entrepreneurs. The technical team through the Social Learning model becomes part of this new community, with a set of associated rules in this new structure. These networks, created through the interactions and a common commitment, generate structures which facilitate communication and knowledge transfer. This process strengthens the social learning among the agents by the combination of experimented knowledge and expert knowledge, assuring a mutual social learning among them achieving "the learning by doing" process. Generating social capital constitutes a key component in the creation, diffusion and knowledge transfer. This is possible by the creation of synergies, networks, and cooperativism among the agents of the territory. 


\section{METHODS}

This study is focused on the Working With People model (WWP) based on the participation of all the agents and stakeholders involved in the project, with a bottom-up approach, and the inclusion of a territorial vision. These components allow shaping the project and are focused on solving the real problems of the population (Ríos-Carmenado et al., 2011). The three pillars of this model are the technical-entrepreneurial component; the ethical-social component; and the political-contextual component. In order to achieve the purpose of this research, WWP model is used to study the generation of social capital through the three components. The model framework is involved in a continuous process of Social Learning regarding the culture, traditions, and values in an attempt to reach a long-term sustainability of the program and the success of the launched projects. In order to facilitate common actions in the social structure, different strategies have been developed to enhance social capital from each component through relationships, rules, commitment, and trust. Strategies included in the Program are based on population empowerment, to increase the capacity to mobilize resources and people; and, the partnership strategy in order to expand the reach of the Program and networks among membership (Bebbington, 2003). Actions included in the strategies encourage the cooperation to achieve the common goal.

To study the generation of social capital in our territory and seek its enhancement, methodology is based on the three WWP pillars. First of them is political-contextual component, providing key elements to meet with the context in which the project is inserted. This area covers relations with public-administrations and political organizations to facilitate participation and social dynamics, allowing changes and adopting priorities of the involved people. Activities carried out in the Program related to political-contextual component, such as interviews and workshops, took place with members of political organisms in the territory, from municipal govern and regional govern. The scope of these activities was to broadcast information of the program and to increase the participation of the population involved using their institutional channels. WWP model confers the project and its organization as a living entity which transmit values to society. Thus, reports were produced by the technical team and given to the municipal govern with the aim to transmit Program information among inhabitants. Furthermore, interest lists were created in an attempt to collect information about future participants, made it possible by cooperation of the municipal government and public sources of information.

On the other hand, the technical-entrepreneurial component of WWP model integrates elements to mobilize human, economical, public, and private resources to lead arrangement and negotiation between stakeholders. In this sense, WWP project adopts a business function assuming and managing the risk. One of the activities included in this component was the realization of workshops focused to businessman established in the territory, and future entrepreneurs who want to launch their new projects. The dynamic of these workshops was focused to collect information about ideas to launch projects, and to create a database according to education requested for population to improve its business capacities, included in the Capacity Building Plan defined in the bases of the Program.

Finally, the ethical-social component is identified with the social subsystem, covering the context of attitudes and values of people involved in the project. Ethics and values are integrated in the project to overcome potential moral conflicts related to the parties involved on it (IPMA, 2006). Reciprocity, trust and cooperation are the strategies needed to assure the success of the Program among the different social levels. Being in touch with the different associations, communities, local action groups (LAG), and other dynamic agents in the territory are necessary to meet the population and broaden on it. In this case, the technical team met different women associations, breeders' organization, GAL operating in the territory (ASOCIO), and the agent of local development, among other. These actions are complementary to the Program and help to expand and strengthen the reach and the social networks existing in the territory (Camagni, 2003).

\section{FINDINGS}

The realization of participatory activities and workshops allow gathering information to analyze how Working With People model influences in the generation of social capital in rural areas. Seven different workshops were carried out between June and September 2014, focused on young people between 18 and 40 years old, and to businessman established in the territory. In December 2014, entrepreneurs were convened again to develop their ideas and to define strategies. In this time, new workshops were focused on specific project ideas encompassed in three axes as a result of the analysis of the data base collected in first activities. The defined axes are agricultural and breeding axis; tourism, culture and crafting axis; and, SMEs and non-agricultural industries axis. As the entrepreneurs' commitment rises to the project idea and the Program, the number of participants in the activities and workshops decreases. In September, after the first round of workshops, the total amount of participants was 153. In December, after the second round, the participation was diminished to 39. First stage, finished in May 2015, gives a total number of 4 projects launched promoted by 7 entrepreneurs.

\section{Ethical-Social component}

Even the participation of the population in the different activities has diminished, the first entrepreneurs in this stage have created close links between them to maintain and support their own projects. It is reflected in the presentation of one of the projects, where the entrepreneur reached to engage more than 150 farmers from the territory to demonstrate the utilities of its project, a rear plough innovation. In this demonstration, all of the seven entrepreneurs included in this first stage were there to help him, organizing the event and supporting logistic issues. Reasons of this solidarity and relationship through the entrepreneurs can be explained by the links created in the workshops and the participation of 
both of them in the Capacity Building Plan. Consequently, solidarity, trust, and commitment among all of them constitute the first step in the creation of social capital.

\section{Technical-Entrepreneurial component}

Other point included in the Program bases is the inclusion of a Capacity Building Plan designed according to population demands expressed in their personal information form. Learning and training initiatives are classified through a Project Management course, an Information and Communication Technologies course and other Specialized Courses in order to contribute to the empowerment of the population and to develop and enhance their professional skills. Sharing the project ideas for the courses included in the Capacity Building Plan has led to the creation of synergies between the projects of this first stage. Citing one of the entrepreneurs, "synergies are created to the main purpose to enhance our region and help each other to achieve the development of these territories". A fact which justifies this affirmation is the entrepreneurs' idea to create a common brand for their products and commercialized them under the same brand. This finding can be related as a result of the strategies used in the technical-entrepreneurial component to promote social capital in the territory as a common action to reach a common profit.

Evaluation of the projects was realized through multicriterial indicators carried out by an Advisory Committee formed by particular professional experts in economic areas and other dynamic agents of the territory. Objective recommendations and assessment were given to this Committee in order to achieve the future success of the projects and a sustainable development in the territory, encourage the entrepreneurs to create synergies among the projects, and contribute to the economic and social development. Due to Advisory Committee's assessment, a set of recommendations are proposed to each project. We should underline the need to remake the Project Inform to complete and improve the business plan. For this reason, it was suggested the participation for all the entrepreneurs on a Course of Accountability to define specifically not only the economic and financial requirements of each project, but also to enhance the financial skills of each entrepreneur to assure the success on each project in the future.

\section{Political-Contextual component}

Activities carried on in the Program share initiatives and measures promoted with other rural development programs, supported by European political strategies at regional level. These types of programs aim to diversify economic activities and to support SME's in the territory, which is in line to the values and principles of the Program that Tatiana Pérez de Guzmán el Bueno Foundation supports. Finally, institutional channels and people's word to mouth have spread the Program information which has resulted in the inclusion of new independent agents, who had not participated on it before or in a direct way, who are interested in joining the Program. This is related to the strategies and actions included in the political-contextual component with regional governments and different promotion events.

\section{CONCLUSIONS}

Social capital can be created through interactions among the social structures inherit in the society: higher levels of social capital in a community, higher levels of trust. Actions towards development and revitalization of the territory should identify different structures of existing social capital in the territories and include tools and strategies to strengthen these structures and to create new ones. This is only possible if social networks and reciprocity are developed in an attempt to enhance the trust among population. Working with People model allows participation of all stakeholders in the planning process, where values such as respect and primacy for the people; endogenous, integrated, and multidisciplinary approach, are included.

Entrepreneurs, who are the main beneficiaries, create new links and relationships to share goals, needs and aspirations within the framework of the program. Findings obtained in this research highlight the need to support actions focused on promoting associationism between territories and seek to reach a project with regional character. It is important to emphasize the need to include actions aimed at young people and women, primarily responsible for retrieving the population in rural areas. The aging of the population in these areas is an unstoppable trend, due to the lack of opportunities and basic services. However, new circumstances as improved communication or the current crisis make the urban population considers the return to rural areas in search of new opportunities. It is also important to encourage those actors who have not participated in the initial stages, for lack of information or lack of interest in the program. It may contribute to the growth of social capital structures in the following stages.

This research evidences social capital can be generated through sense of belonging to the same area, social identity, and common values. On the other hand, social learning component included in WWP model provides the project an integrating component to ensure space and social learning process among the different social structures and subsystems. Reality change and experience are key factors for the effective learning to generate actions directed to promote a mutual learning, integrating the experienced knowledge with the planner's expertise. In this sense, the involvement of the University in this kind of initiatives promotes knowledge transfer and the creation of new links with other external agents who share common goals. Thus, the scope of the program goes beyond its limits, involving new actors such as external businessmen and experts in different economic activities. It is important to disseminate, monitoring, and program information, results and program news, in order to continue the process of creating social capital.

To conclude this communication, the three components of WWP model show how social capital can be generated through the different structures inherit in society. Findings show that the three components, which are not mutually exclusive, can be shared to analyze the impact of different strategies. 


\section{REFERENCES}

1. Afonso Gallegos, A., Herrera Hernández, O. B., Barrantes, C., Cazorla Montero, A., Nicolás, V. L. de, Ríos Carmenado, I. de L., Diaz Puente, J. M., Fontana Palacios, A., Fernández Moral, M. J., Fetterman, D., Fitzgerald, C. S., Gómez Gajardo, F., Hernández, D., Midgley, J., Parra Vázquez, M. R., Sastre Merino, S., Vidueira, P., Yagüe Blanco, J. L. 2012. Planning and community development: case studies. $306 \mathrm{p}$.

2. Bebbington, A. 2003. El capital social en el desarrollo: teoría conceptos o estrategia, "Capital social: potencialidades analíticas y metodológicas para la superación de la pobreza", serie Seminarios y conferencias, N 31 (LC/L. 1969-P), Arriagada, Irma y Francisca Miranda (comps.), Santiago de Chile, Comisión Económica para América Latina y el Caribe (CEPAL). Publicación de las Naciones Unidas, Nde venta: $S$, 3. (In Spain)

3. Bowles, S., Gintis, H. 2004. Persistent parochialism: trust and exclusion in ethnic networks. Journal of Economic Behavior \& Organization, Vol. 55, Iss. 1, pp. 1-23.

4. Bhandari, H., Yasunobu, K. 2009. What is Social Capital? A Comprehensive Review of the Concept. Asian Journal of Social Science, Vol. 37, Iss. 3, pp. 480-510.

5. Bourdieu, P. 2011. The forms of capital (1986). Cultural theory: An anthology, pp. 81-93.

6. Camagni, R. 2003. Incertidumbre, capital social y desarrollo local: enseñanzas para una gobernabilidad sostenible del territorio. Investigaciones regionales, Vol. 2, pp. 31-58. (In Spain)

7. Cazorla, A., De los Ríos, I., Morales, J. 2006. Modelos de planificación y políticas de investigación para la lucha contra el hambre y la pobreza. El fin del hambre en el, 2025, 273-317. (In Spain)

8. Cazorla, A., De los Ríos, I., Salvo, M., (2013) Working With People (WWP) in Rural Development Projects: a Proposal from Social Learning. Cuadernos de Desarrollo Rural, Vol. 10, Iss. 70, pp. 131-157.

9. Cohen, J. M., Uphoff, N. T. 1980. Participation's place in rural development: seeking clarity through specificity. World development, Vol. 8, Iss. 3, pp. 213-235.

10. Coleman, J. S. 1988. Social capital in the creation of human capital. American journal of sociology, S95-S120.

11. Fafchamps, M. 2004. Social capital and development. Department of Economics, University of Oxford.

12. Friedmann, J. 1992. Empowerment: the politics of alternative development. Blackwell.

13. Friedmann, J. 1987. Planning in the public domain: from knowledge to action. Princeton University Press.

14. Fukuyama, F. 1995. Trust: The social virtues and the creation of prosperity (No. D10 301 c. 1/c. 2). New York: Free press.

15. Hanifan, L. J. 1916. The rural school community center. Annals of the American Academy of political and Social Science, Vol. 67, pp. $130-138$.

16. Hjerppe, R. 1998. Social capital and economic growth. Government Institute for Economic Research.

17. International Project Management Association. 2006. ICB-NCB IPMA competence baseline, version 3.0. Nijkerk, Author, 212.

18. Mandarano, L. A. 2009. Social network analysis of social capital in collaborative planning. Society and natural resources, Vol. 22, Iss. 3, pp. 245-260.

19. Michelini, J. J. 2013. Small farmers and social capital in development projects: Lessons from failures in Argentina's rural periphery. Journal of Rural Studies, Vol. 30, pp. 99-109.

20. Narayan-Parker, D. 1999. Bonds and bridges: social capital and poverty. Vol. 2167. World Bank Publications.

21. Portes, A. 2000. Social capital: Its origins and applications in modern sociology. LESSER, Eric L. Knowledge and Social Capital. Boston: Butterworth-Heinemann, pp. 43-67.

22. Putnam, R. D. 1995. Bowling alone: America's declining social capital. Journal of Democracy, Vol. 6, Iss. 1, pp. 65-78.

23. Ríos-Carmenado, I. D. L., Díaz-Puente, J. M., Cadena-Iñiguez, J. 2011. La iniciativa LEADER como modelo de desarrollo rural: Aplicación a algunos territorios de México. Agrociencia, Vol. 45, Iss. 5, pp. 609-624. (In Spain)

24. Sastre, S., Fernández, M. J. 2012. Social capital measurements for community development in rural areas. Planning and community development: case studies, $69 \mathrm{p}$.

25. Stolle, D. 2003. The sources of social capital. Palgrave Macmillan. pp. 19-42.

26. Woolcock, M. 1998. Social capital and economic development: Toward a theoretical synthesis and policy framework. Theory and society, Vol. 27, Iss. 2, pp. 151-208. 